Supporting Information

\title{
Compound-Specific Nitrogen and Carbon Isotope Analysis of Nitroaromatic Compounds in Aqueous Environmental Samples Using SPME Coupled to GC-IRMS
}

Michael Berg, Jakov Bolotin, and Thomas B. Hofstetter*

Eawag, Swiss Federal Institute of Aquatic Science (Eawag), 8600 Dübendorf, Switzerland, and Institute of Biogeochemistry and Pollutant Dynamics, ETH Zurich, 8092 Zurich, Switzerland

\section{Contents:}

Figures: 1

Pages: 2 

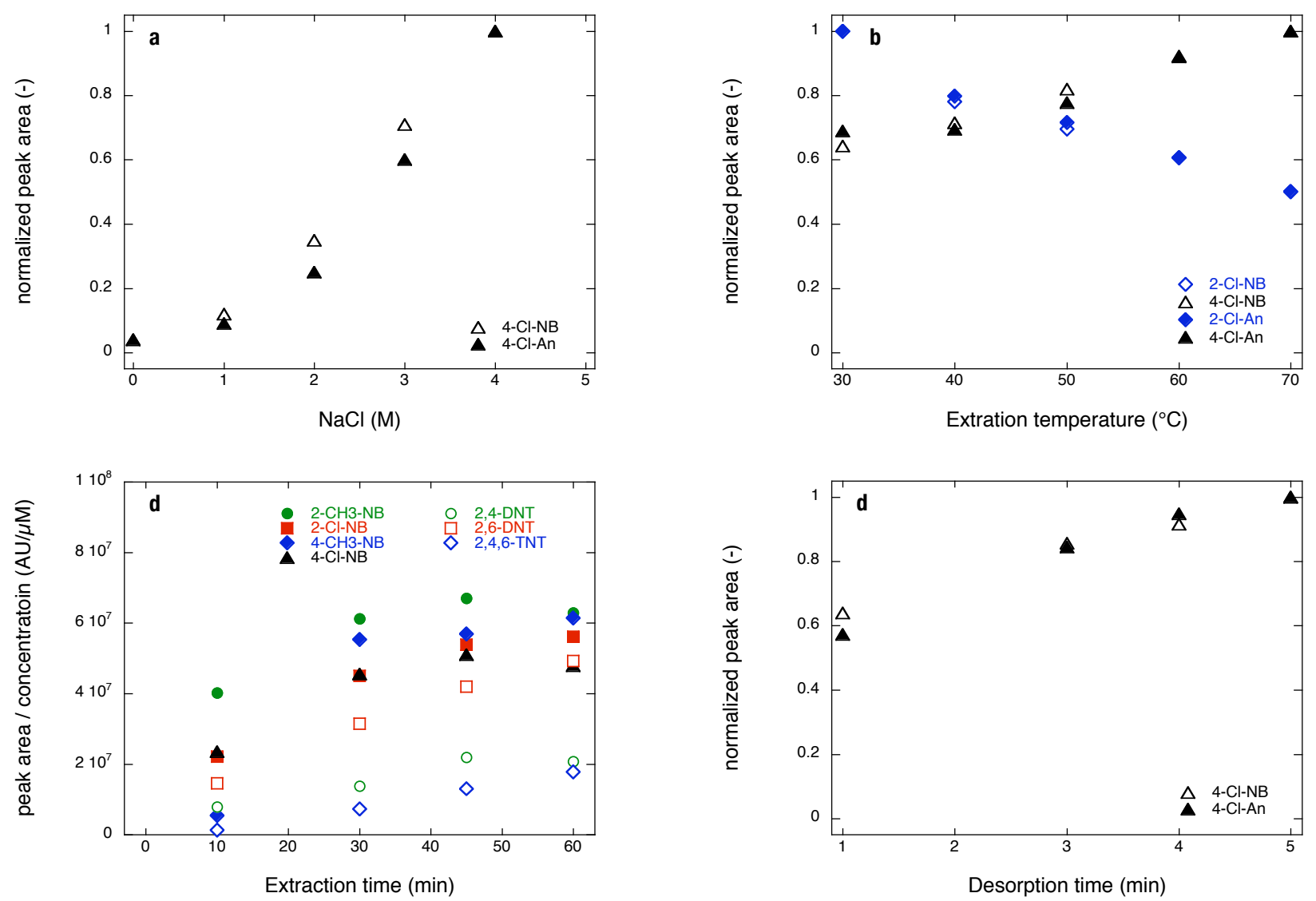

Figure S1: Influence of various SPME parameters on the extraction efficiency of selected nitroaromatic compounds and substituted anilines: (a) $\mathrm{NaCl}$ concentration, (b) extraction temperature, (c) extraction time, (d) desorption time. Abbreviations were as follows nitrotoluenes $\left(\mathrm{CH}_{3}-\mathrm{NB}\right)$, chloro-nitrobenzenes (Cl-NB), dinitrotoluenes (DNT), trinitrotoluene (TNT), methyl-anilines $\left(\mathrm{CH}_{3}-\mathrm{An}\right)$, chloro-anilines (Cl-An). For final SPME-GC/MS and SPME-GC/IRMS-measurements experimental conditions were $4 \mathrm{M} \mathrm{NaCl}, 45^{\circ} \mathrm{C}$ extraction temperature, $35 \mathrm{~min}$ extraction time, $3 \mathrm{~min}$ desorption time. Desorption temperature was $270^{\circ} \mathrm{C}$. 